\title{
Avaliação econômica de três tipos de suplementação mineral para bovinos de corte no Estado do Pará ${ }^{1}$
}

\author{
Francisberto B. Barbosa ${ }^{2}$, Henrique A. Bomjardim² ${ }^{2}$, Michel José S.A. Helayel ${ }^{3}$, Kelson C.F. \\ Faial $^{4}$, Carlos M.C. Oliveira ${ }^{2}$, Pedro Malafaia ${ }^{5}$, Marilene F. Brito ${ }^{6}$ e José D. Barbosa ${ }^{2 *}$
}

\begin{abstract}
Barbosa F.B., Bomjardim H.A., Helayel M.J.S.A., Faial K.C.F., Oliveira C.M.C., Malafaia P., Brito M.F. \& Barbosa J.D. 2016. [Economic evaluation of three strategies of mineral supplementation for beef cattle in State of Pará, Brazil.] Avaliação econômica de três tipos de suplementação mineral para bovinos de corte no estado do Pará. Pesquisa Veterinária Brasileira 36(7):600-604. Instituto de Medicina Veterinária, Faculdade de Medicina Veterinária, Universidade Federal do Pará, Campus de Castanhal, Rodovia BR-316 Km 61, Castanhal, PA 68741-740, Brazil. E-mail: diomedes@ufpa.br

Three alternatives of mineral supplementation of 18 to 20-month-old male Nelore cattle with 299.5 to $308.5 \mathrm{~kg}$ of body weight were used at a farm in northeast of Pará state, Brazil. To evaluate which mineral mixture resulted in better cost-benefit, three groups of 20 head were supplemented for six months, from March to August of 2012. Group 1 was supplemented with a selected mineral mixture (SMM) composed of $25 \mathrm{~kg} \mathrm{NaCl}, 50 \mathrm{~kg}$ dicalcium phosphate, $190 \mathrm{~g}$ copper sulphate, $60 \mathrm{~g}$ cobalt sulphate, and $15 \mathrm{~g}$ sodium selenite, having $133 \mathrm{~g} \mathrm{Na}, 123 \mathrm{~g} \mathrm{P}, 631 \mathrm{mg} \mathrm{Cu}, 167 \mathrm{mg} \mathrm{Co}$, and $9 \mathrm{mg}$ Se per kg; this mixture was made based in previous clinical-nutritional examination of herd. Group 2 (control), supplemented only with $\mathrm{NaCl}$; and group 3 received a commercial mineral mixture (CMM), routinely used in this farm, with $130 \mathrm{~g} \mathrm{P}, 220 \mathrm{~g} \mathrm{Ca}, 18 \mathrm{~g} \mathrm{Mg}, 36 \mathrm{~g} \mathrm{~S}, 6000 \mathrm{mg} \mathrm{Zn,} 1500 \mathrm{mg} \mathrm{Cu}, 2000 \mathrm{mg}$ Mn, 200mg Co, 90mg I, and 36mg Se per kg. Concentrations of phosphorus, copper, zinc and iron were determined in liver and 12th ribs. The best cost-benefit alternative was the SMM; the forage alone did not contain enough Co to meet the requirements of the control group, but provided enough $\mathrm{P}, \mathrm{Cu}, \mathrm{Zn}$ and Se during the five months of the experiment.
\end{abstract}

INDEX TERMS: Cattle, mineral deficiencies, mineral supplementation.

RESUMO.- Em uma propriedade localizada na região nordeste do Estado do Pará foram analisadas alternativas de suplementação mineral para bovinos de corte, da raça nelore, machos, com idades entre 18 e 20 me-

\footnotetext{
${ }^{1}$ Recebido em 23 de março de 2016.

Aceito para publicação em 4 de maio de 2016.

${ }^{2}$ Instituto de Medicina Veterinária, Faculdade de Medicina Veterinária, Universidade Federal do Pará (UFPA), Campus de Castanhal, Rodovia BR316 Km 61, Castanhal, PA 68741-740, Brasil. *Autor para correspondência:diomedes@ufpa.br

${ }^{3}$ Universidade Federal do Tocantins, (UFT), BR-153 Km 112, Araguaína, TO 77800-000, Brasil.

${ }^{4}$ Laboratório de Toxicologia "Edilson Brabo", Seção de Meio Ambiente (SAMAM), Instituto Evandro Chagas, Rodovia BR-316 Km 7, Levilândia, Ananideua, PA 67030-000, Brasil.

${ }^{5}$ Departamento de Nutrição Animal e Pastagem, Instituto de Zootecnia, Universidade Federal Rural do Rio de Janeiro (UFRRJ), Seropédica, RJ 23851-970, Brasil.

${ }^{6}$ Departamento de Epidemiologia e Saúde Pública, Instituto de Veterinária, UFRRJ, Seropédica, RJ 23890-000, Brasil.
}

ses e pesos de 299,5 a 308,5 kg. Foram avaliados o custo benefício, os valores dos minerais no fígado e nas costelas e o ganho de peso médio diário dos animais submetidos aos diferentes tratamentos. 0 estudo foi realizado durante seis meses (março a agosto de 2012), no período de ótima oferta de pastagem. Foram utilizados 60 bovinos, divididos em três grupos de 20 animais em delineamento experimental inteiramente casualizado. 0 Grupo 1 foi suplementado com uma mistura mineral seletiva (MMS) composta por $25 \mathrm{~kg}$ de $\mathrm{NaCl}, 50 \mathrm{~kg}$ de fosfato bicálcico, $190 \mathrm{~g}$ de sulfato de Cobre, $60 \mathrm{~g}$ de sulfato de Cobalto e $15 \mathrm{~g}$ de selenito de sódio; essa mistura continha, em um quilograma, 133g de $\mathrm{Na}, 123 \mathrm{~g}$ de $\mathrm{P}, 631 \mathrm{mg}$ de $\mathrm{Cu}$, $167 \mathrm{mg}$ de Co e $9 \mathrm{mg}$ de Se; essa mistura foi proposta com base no prévio diagnóstico clínico-nutricional do rebanho. $\mathrm{O}$ Grupo 2 foi suplementado apenas com $\mathrm{NaCl}$ (Grupo controle) e o Grupo 3 recebeu uma mistura mineral comercial (MMC), rotineiramente utilizada na fazenda, contendo, em um quilograma, $130 \mathrm{~g}$ de $\mathrm{P}, 220 \mathrm{~g}$ de $\mathrm{Ca}, 18 \mathrm{~g}$ 
de $\mathrm{Mg}$, 36g de S, $6.000 \mathrm{mg}$ de $\mathrm{Zn}, 1.500 \mathrm{mg}$ de $\mathrm{Cu}, 2.000 \mathrm{mg}$ de $\mathrm{Mn}, 200 \mathrm{mg}$ de Co, $90 \mathrm{mg}$ de I e $36 \mathrm{mg}$ de Se. 0 melhor custo benefício foi obtido com a mistura mineral seletiva. A pastagem não contém Co suficiente para atender as necessidades dos bovinos do grupo controle, mas foi capaz de suprir as necessidades de P, $\mathrm{Cu}, \mathrm{Zn}$ e Se durante os cinco meses do experimento.

TERMOS DE INDEXAÇÃO: Bovinos, deficiência mineral, suplementação mineral.

\section{INTRODUÇÃO}

O Estado do Pará possui hoje a maior fronteira agrícola em toda a Amazônia legal, por isso possui potencialidades incomensuráveis e importância econômico-social.

Na região Amazônica estima-se que haja um rebanho de 42 milhões de bovinos, com destaque para o estado do Pará, com uma população bovina de aproximadamente 17,5 milhões de cabeças (AnualPec 2014). A maioria desses animais é de origem zebuína e é destinada à produção de carne. 0 sistema de criação predominante é o extensivo, baseado em pastagens dos gêneros Brachiaria (Sinonímia Urochloa) e Panicum, e a suplementação mineral é realizada, na maioria das vezes, através de misturas minerais comerciais, adquiridas sem o prévio diagnóstico clínico-nutricional dos rebanhos. Tal prática é antieconômica e já foi demonstrada em outras pesquisas (Malafaia et al. 2004, Carvalho et al. 2014).

Bovinos criados em pastagens podem ter o crescimento comprometido se a quantidade dos minerais essenciais não atenderem as exigências dietéticas, mesmo em condições de excelente oferta de forragem. Os desequilíbrios minerais (deficiências ou excessos) nos solos e forrageiras vêm sendo, ao longo do tempo, responsabilizados pelo baixo desempenho produtivo e reprodutivo de ruminantes sob pastejo em áreas tropicais (Tokarnia \& Döbereiner 1973, Van Niekerk \& Jacobs 1985, Tokarnia et al. 2000, Tokarnia et al. 2010).

No Estado do Pará, estudos realizados por Tokarnia et al. (1999) e Tokarnia et al. (2010) demonstraram que as deficiências mais importantes são as deficiências de fósforo $(\mathrm{P})$, cobre $(\mathrm{Cu})$, cobalto (Co), zinco $(\mathrm{Zn})$ e selênio (Se). Baseado nestes conhecimentos pressupõe-se que seriam esses os minerais que deveriam constar nas misturas minerais disponibilizadas aos bovinos e em concentração adequada à realidade das fazendas. Contudo, na maioria das vezes, esses conhecimentos não são "adotados" por profissionais e pecuaristas que persistem em estimular o uso generalizado de suplementos minerais comerciais com diversos elementos como cálcio (Ca), magnésio $(\mathrm{Mg})$, enxofre(S), ferro $(\mathrm{Fe})$, manganês $(\mathrm{Mn})$, níquel $(\mathrm{Ni})$, cromo $(\mathrm{Cr})$ e outros. Deficiências essas que não ocorrem em bovinos criados em pastagens, sob condições naturais, ou que só existem em situações muito particulares e raras (Malafaia et al. 2004, Malafaia et al. 2014).

Dessa forma, o objetivo deste trabalho foi avaliar as despesas com a utilização de três diferentes misturas minerais, assim como o seu efeito na saúde e desempenho produtivo dos animais.

\section{MATERIAL E MÉTODOS}

Local do estudo. 0 experimento foi realizado em uma propriedade localizada no município de Cachoeira do Piriá, nordeste do Estado do Pará (140'15" S e 46³1'44" W).

Animais. Foram utilizados 60 bovinos, da raça Nelore, machos, com idades de 18 a 20 meses, com pesos entre 299,5 e 308,5 $\mathrm{kg}$, mantidos em piquetes com boa oferta de forragem, composta por aproximadamente $70 \%$ de Brachiaria (Sinonímia Urochloa) decumbens e 30\% Panicum maximum cv. Mombaça. Antes do início do experimento todos os animais foram previamente pesados, após jejum completo de 12 horas, e tratados com ivermectina a $1 \%$ na dose de $1 \mathrm{mg} / \mathrm{kg}$ de peso.

Grupos experimentais. Os animais foram identificados e separados em três grupos de 20 animais, que receberam três diferentes misturas minerais durante seis meses (março-agosto, período de ótima oferta de pastagem na região). 0 Grupo 1 foi suplementado com uma mistura mineral seletiva (MMS) composta por $25 \mathrm{~kg}$ de cloreto de sódio $(\mathrm{NaCl}), 50 \mathrm{~kg}$ de fosfato bicálcico,190g de sulfato de $\mathrm{Cu}, 60 \mathrm{~g}$ de sulfato de Co e $15 \mathrm{~g}$ de selenito de sódio; essa mistura continha, por $\mathrm{kg}, 133 \mathrm{~g}$ de $\mathrm{Na}$, $123 \mathrm{~g}$ de $\mathrm{P}, 631 \mathrm{mg}$ de $\mathrm{Cu}, 167 \mathrm{mg}$ de Co e $9 \mathrm{mg}$ de Se; essa mistura foi proposta com base no prévio diagnóstico clínico-nutricional do rebanho. 0 Grupo 2 foi suplementado apenas com sal comum $(\mathrm{NaCl})$ (Grupo controle) e o Grupo 3 recebeu uma mistura mineral comercial (MMC), rotineiramente utilizada na fazenda, contendo, em cada $\mathrm{kg}, 130 \mathrm{~g}$ de $\mathrm{P}, 220 \mathrm{~g}$ de $\mathrm{Ca}, 18 \mathrm{~g}$ de $\mathrm{Mg}, 36 \mathrm{~g}$ de $\mathrm{S}$, $6000 \mathrm{mg}$ de $\mathrm{Zn}, 1.500 \mathrm{mg}$ de $\mathrm{Cu}, 2.000 \mathrm{mg}$ de $\mathrm{Mn}, 200 \mathrm{mg}$ de Co, $90 \mathrm{mg}$ de I e $36 \mathrm{mg}$ de Se.

Durante o período experimental, a cada 30 dias, foram realizadas coletas de dados. Foram estimados o consumo dos três suplementos minerais testados, realizada a pesagem e o exame clínico dos animais. Ao final de cada período de coletas, os animais eram trocados de piquetes, a fim de minimizar o efeito do local de pastejo. A reposição dos suplementos minerais era feita semanalmente, durante o manejo normal da fazenda, ou sempre que os cochos estivessem pouco abastecidos, de forma a não permitir a ausência dos suplementos. Os suplementos minerais custavam 1,46, 0,40 e $1,50 \mathrm{R} \$ / \mathrm{kg}$, para a MMS, $\mathrm{NaCl}$ e MMC, respectivamente.

Biópsia de costela e fígado. Ao final do experimento 10 animais de cada grupo foram selecionados aleatoriamente para a coleta de amostras, por meio de biópsias, do tecido ósseo e hepático. As biópsias foram realizadas no bordo cranial do terço superior da $12^{\text {a }}$ costela do lado direito e no bordo caudal do lobo caudado do fígado, pela metodologia empregada por Bomjardim et al. (2015).

Avaliação químico-física das biópsias do tecido ósseo. Depois de descongeladas à temperatura ambiente, as amostras foram secas, pesadas em balança analítica e colocadas em uma proveta com $10 \mathrm{~mL}$ de água para se determinar o volume de água deslocado. 0 cálculo da densidade óssea em água foi efetuado segundo Fick et al. (1979). Em seguida, as amostras foram secas a $105^{\circ} \mathrm{C}$ durante $12 \mathrm{~h}$ e desengorduradas com éter etílico durante 48h. Após secas e livres de gordura, as amostras foram pesadas, calcinadas a $600^{\circ} \mathrm{C}$ durante $12 \mathrm{~h}$ e trituradas em gral e pistilo para a obtenção das cinzas ósseas.

Para a determinação do P nas cinzas ósseas cada amostra foi pesada entre 0,25 a $0,26 \mathrm{~g}$ e colocada com $3 \mathrm{~mL}$ de ácido nítrico, $1 \mathrm{~mL}$ de ácido clorídrico a $30 \%$ e $1 \mathrm{~mL}$ de peróxido de hidrogênio a $30 \%$. As amostras ficaram em repouso durante $12 \mathrm{~h}$ para a pré-digestão. Depois, foram colocadas em forno micro-ondas (MARSXpress, CEM Corp. Matthews, NC, USA) para a digestão final e aquecidas em quatro etapas com 800W de potência e duração de 10 min para cada etapa.Após a digestão, as amostras foram transferidas para tubos Falcon. Em cada tubo foram adicionados $50 \mathrm{~mL}$ 
de água deionizada e desta solução foi retirado $1 \mathrm{~mL}$ e colocado em outro tubo Falcon, no qual foram acrescidos $49 \mathrm{~mL}$ de água deionizada formando um volume final de $50 \mathrm{~mL}$. Para determinação do fosfato $\left(\mathrm{PO}_{4}^{3-}\right)$, foi retirado aproximadamente $5 \mathrm{~mL}$ dessa solução para ser analisada por cromatografia de íons, em sistema ICS 2000 DUAL (Thermo Scientific-Dionex, USA).

Análises de minerais no fígado. As amostras hepáticas foram seccionadas em fatias finas utilizando-se navalhas de aço inoxidável, armazenadas em tubos de polipropileno de $50 \mathrm{~mL}$ e submetidas ao processo de liofilização. Para esse processo, as amostras, congeladas a $-20^{\circ} \mathrm{C}$, foram colocadas em bandejas no aparelho automatizado LIOTOP $^{\circledR}$ (modelo L101), a uma temperatura de $-55^{\circ} \mathrm{C}$, as quais permaneceram por um período de $24 \mathrm{~h}$ para a secagem completa. Posteriormente, as amostras foram trituradas em grau e pistilo. Para a determinação dos minerais $\mathrm{Cu}$, $\mathrm{Co}, \mathrm{Se}, \mathrm{Zn}, \mathrm{Fe}$ e $\mathrm{Mn}$, as amostras trituradas foram pesadas entre 0,25 a 0,26g e colocadas em tubo de digestão de Teflon (modelo Xpress). Em seguida, foram adicionados $3 \mathrm{~mL}$ de ácido nítrico a $65 \%, 1 \mathrm{~mL}$ de ácido clorídrico a $30 \%$ e $1 \mathrm{~mL}$ de peróxido de hidrogênio a $30 \%$. As amostras ficaram em repouso durante $2 \mathrm{~h}$ para uma pré-digestão e digeridas por $50 \mathrm{~min}$ em sistema fechado por radiação de micro-ondas (MARSXpress, CEM Corp. Matthews, NC, USA). Após a digestão, os minerais $\mathrm{Cu}, \mathrm{Co}, \mathrm{Zn}, \mathrm{Fe}$ e $\mathrm{Mn}$ foram analisados pela técnica de espectrometria de emissão ótica com plasma induzido (ICP OES) no equipamento ICP-OES (Vista-MPX CCD simultâneo, axial da VARIAN) em sistema de amostragem automático (SPS-5). Já o Se foi determinado pela técnica de espectometria de emissão ótica com acoplamento de geração de hidretos (HG-ICP OES) no equipamento modelo iCAP 6000 - CCD simultâneo (ThermoScientific, Madison, USA), configuração axial e equipado com sistema de amostragem automático (CETAC - ASX 520). 0 controle das condições operacionais do ICP OES foi realizado com o software iTEVA. Os brancos analíticos foram preparados pelos mesmos procedimentos, porém, sem a adição das amostras de fígado (Nomura et al. 2005).

Análise estatística. As variáveis foram descritas com as respectivas médias e seus intervalos de confiança. Os dados foram, inicialmente, testados quanto à sua distribuição normal, utilizando-se o teste de Kolmogorov-Smirnov e depois foram submetidos à análise de variância. Foi aplicado o nível de significância de $5 \% \mathrm{e}$ a diferença mínima significativa foi estimada pelo teste de Student Newman-Keuls. As análises foram feitas por meio do programa Statistical Analysis System (SAS 2010). O intervalo de confiança adotado foi de $95 \%$ e foi calculado como sendo o erro-padrão da média multiplicado por 1,96.

\section{RESULTADOS}

Os resultados médios de consumo e despesas de cada grupo experimental, bem como o ganho de peso dos três tipos de suplementação mineral constam no Quadro 1. 0 maior consumo diário foi observado no grupo que recebeu a mistura mineral comercial (MMC), seguido por aqueles que receberam somente cloreto de sódio $(\mathrm{NaCl})$ e a mistura mineral seletiva (MMS) (Quadro 1).

Com relação ao aspecto econômico, o grupo que recebeu a MMC teve a maior despesa, seguida pelos grupos que receberam a MMS e somente o $\mathrm{NaCl}$ (Quadro 1).

Os animais suplementados com a MMS tiveram os maiores ganhos de peso, seguidos daqueles que receberam MMC (Quadro 1). 0 menor ganho de peso foi observado nos animais que receberam apenas o $\mathrm{NaCl}$ (Quadro 1).

Baseado nas fórmulas das misturas minerais e na média das ingestões diárias verificou-se que os animais dos grupos suplementados com a MMS e com a MMC ingeriram 4,38 e 9,98g P por animal/dia, respectivamente (Quadro 2).

Os animais suplementados com a MMC consumiram $135 \%$ de $\mathrm{NaCl}, 127,8 \%$ de $\mathrm{P}, 412 \%$ de $\mathrm{Cu}, 161 \%$ Co e $762,5 \%$ de Se a mais, em relação aos animais que receberam a MMS.

A ingestão média diária de $\mathrm{Cu}$ no grupo que recebeu a MMC foi 5,12 vezes maior do que no grupo que recebeu a MMS.

No Quadro 3 encontram-se os valores médios da densidade óssea em água, cinzas ósseas e dos teores de $\mathrm{P}$ e de microelementos no fígado de bovinos que receberam diferentes tipos de suplementação mineral. Os grupos suplementados com $\mathrm{NaCl}$ e com a MMS tiveram as menores densidades ósseas em água. Com relação às cinzas ósseas e a porcentagem de $\mathrm{P}$ no osso não foram observadas diferenças significativas entre os três grupos experimentais.

0 grupo suplementado apenas com $\mathrm{NaCl}$ teve os menores valores hepáticos de Co e Fe e os maiores teores de $\mathrm{Cu}, \mathrm{Zn}$ e Mn (Quadro 4). 0 grupo suplementado com a MMS teve as maiores concentrações hepáticas de Co e Fe, enquanto que os animais que ingeriram a MMC tiveram os maiores valores hepáticos para Se e Mn (Quadro 4).

\section{DISCUSSÃO}

O melhor custo-benefício entre as diferentes suplementações foi obtido com a MMS, pois a suplementação apenas com $\mathrm{NaCl}$ resultou na menor despesa, porém não resultou em maior ganho de peso. 0 fornecimento da MMC proporcionou a maior despesa e um ganho de peso menor do que a suplementação com a MMS. A despesa com a MMS foi 2,22 vezes menor, quando comparada com a MMC e proporcionou um ganho de peso $20 \%$ superior nos animais deste grupo (Quadro 1). Desta forma, o maior número de elementos minerais em uma mistura mineral não significa que ela promova um melhor custo-benefício para os fazendeiros, como ficou demonstrado neste estudo. Similarmente, Carvalho et al. (2014) avaliaram o desempenho

Quadro 1. Consumo, despesas e ganho de peso de bovinos que receberam diferentes tipos de suplementação mineral

\begin{tabular}{lccc}
\hline \multirow{2}{*}{ Parâmetros } & \multicolumn{3}{c}{ Tipos de suplementação mineral } \\
\cline { 2 - 4 } & MMS & NaCl & MMC \\
\hline Consumo médio diário de suplemento (g/animal) & $35,6^{\mathrm{c}}$ & $58,4^{\mathrm{b}}$ & $76,8^{\mathrm{a}}$ \\
Despesas diárias com a suplementação (R\$/animal/dia) & $0,052^{\mathrm{b}}$ & $0,023^{\mathrm{c}}$ & $0,115^{\mathrm{a}}$ \\
Consumo mensal dos suplementos (kg/grupo) & $21,4^{\mathrm{c}}$ & $35,0^{\mathrm{b}}$ & $46,1^{\mathrm{a}}$ \\
Despesa mensal com a suplementação (R\$/grupo) & $31,2^{\mathrm{b}}$ & $14,0^{\mathrm{c}}$ & $69,1^{\mathrm{a}}$ \\
Ganho médio de peso (g/dia) & $962,2^{\mathrm{a}} \pm 67,2$ & $430,7^{\mathrm{c}} \pm 111,2$ & $778,7^{\mathrm{b}} \pm 25,8$
\end{tabular}

Letras minúsculas na mesma linha diferem entre si ao nível de $5 \%$ de probabilidade. 
Quadro 2. Consumo médio diário de cloreto de sódio e de minerais nos diferentes grupos a partir da média de consumo dos diferentes tipos de suplementação mineral

\begin{tabular}{lccc}
\hline Elementos & \multicolumn{3}{c}{ Tipos de suplementação mineral } \\
\cline { 2 - 4 } & MMS & NaCl & MMC \\
\hline NaCl (g) & 11,8 & 58,4 & 27,8 \\
$\mathrm{P}(\mathrm{g})$ & 4,38 & - & 9,98 \\
$\mathrm{Cu}(\mathrm{mg})$ & 22,5 & - & 115,2 \\
$\mathrm{Co}(\mathrm{mg})$ & 5,90 & - & 15,4 \\
$\mathrm{Se}(\mathrm{mg})$ & 0,32 & - & 2,76
\end{tabular}

Quadro 3. Valores médios e intervalos de confiança da densidade óssea, cinzas ósseas e teores de P no osso de bovinos que receberam diferentes tipos de suplementação mineral

\begin{tabular}{lccc}
\hline Parâmetros & \multicolumn{3}{c}{ Tipos de suplementação mineral } \\
\cline { 2 - 4 } & MMS & NaCl & MMC \\
\hline Densidade óssea (g/cm3) & $1,58^{\mathrm{b}} \pm 0,08$ & $1,56^{\mathrm{b}} \pm 0,13$ & $1,65^{\mathrm{a}} \pm 0,06$ \\
Cinzas ósseas (\%MS) & $61,6^{\mathrm{a}} \pm 0,79$ & $60,6^{\mathrm{a}} \pm 0,93$ & $61,5^{\mathrm{a}} \pm 0,68$ \\
P nas cinzas ósseas (\%MS) & $13,7^{\mathrm{a}} \pm 0,21$ & $13,3^{\mathrm{a}} \pm 0,23$ & $13,7^{\mathrm{a}} \pm 0,24$
\end{tabular}

Letras minúsculas na mesma linha diferem entre si ao nível de $5 \%$ de probabilidade.

Quadro 4. Valores médios e intervalos de confiança de microminerais no fígado dos bovinos que receberam diferentes tipos de suplementação mineral

\begin{tabular}{lccc}
\hline Elementos (mg/kg) & \multicolumn{3}{c}{ Tipos de suplementação mineral } \\
\cline { 2 - 4 } & MMS & NaCl & MMC \\
\hline Co & $1,20^{\mathrm{a}} \pm 0,34$ & $0,22^{\mathrm{c}} \pm 0,05$ & $0,55^{\mathrm{b}} \pm 0,20$ \\
$\mathrm{Cu}$ & $351,2^{\mathrm{c}} \pm 61,8$ & $431,9^{\mathrm{a}} \pm 109,8$ & $401,4^{\mathrm{b}} \pm 75,2$ \\
$\mathrm{Se}$ & $0,44^{\mathrm{c}} \pm 0,13$ & $0,48^{\mathrm{b}} \pm 0,14$ & $0,53^{\mathrm{a}} \pm 0,12$ \\
$\mathrm{Zn}$ & $156,1^{\mathrm{b}} \pm 16,1$ & $167,5^{\mathrm{a}} \pm 21,6$ & $154,4^{\mathrm{b}} \pm 23,4$ \\
$\mathrm{Fe}$ & $491,6^{\mathrm{a}} \pm 73,3$ & $400,7^{\mathrm{c}} \pm 64,9$ & $429,3^{\mathrm{b}} \pm 112,2$ \\
$\mathrm{Mn}$ & $15,9^{\mathrm{b}} \pm 1,21$ & $17,8^{\mathrm{a}} \pm 2,59$ & $17,1^{\mathrm{a}} \pm 1,93$
\end{tabular}

Letras minúsculas na mesma linha diferem entre si ao nível de $5 \%$ de probabilidade.

de novilhas leiteiras em pastagem de capim-Xaraés (Urochloa brizantha cv. Xaraés) suplementadas com MMS ou MMC e concluíram que o custo-benefício foi maior para os animais suplementados com a MMS. Malafaia et al. (2004) avaliaram, em quatro propriedades, o desempenho ponderal de bovinos de corte, criados a campo, que consumiram MMS ou MMC; em três fazendas, o ganho de peso diário foi maior para os grupos de animais que receberam a MMS.

$\mathrm{O}$ menor consumo de $\mathrm{NaCl}$ pelos animais que receberam a MMS se deveu ao fato de que essa mistura mineral tenha sido formulada com $66,5 \%$ de fosfato bicálcico, que é um ingrediente pouco palatável aos bovinos. De acordo com Tokarnia et al. (2010), a média diária para o consumo de $\mathrm{NaCl}$ é de $30 \mathrm{~g}$ por animal e a quantidade de $\mathrm{NaCl}$ numa mistura mineral determina a quantidade da mesma a ser ingerida, podendo ter ao mesmo tempo efeito estimulatório ou limitante da sua ingestão.

Apenas no grupo suplementado com a MMC a ingestão média diária de $\mathrm{P}$ foi superior a $6 \mathrm{~g} / \mathrm{animal}$; o que de acordo com Tokarnia et al. (2010) seria a quantidade suficiente para um desenvolvimento satisfatório e para que os animais não venham a apresentar sinais clínicos da deficiência de fósforo.
Com relação ao efeito da suplementação sobre a \% de P nas cinzas ósseas, verificou-se que todos os grupos apresentaram valores considerados normais para a espécie bovina, que é acima de 11,5\% (McDowell et al. 1984). Nos três grupos experimentais a densidade específica óssea foi inferior ao valor de referência para a espécie bovina, que é $1,69 \mathrm{~g} / \mathrm{cm}^{3}$ (Valdes et al. 1988). 0 grande problema é que na maioria dos artigos, os valores médios de referência não vêm acompanhados de seus respectivos intervalos de confiança, não sendo possível estimar os valores mínimos e máximos para cada parâmetro analisado. No entanto, segundo Riet-Correa \& Timm (2007) e Radostits et al. (2007) o conteúdo de $\mathrm{P}$ nas cinzas ósseas ainda é considerado o mais acurado indicador do status fosfórico dos bovinos. Verificou-se que todos os animais tiveram valores normais para o porcentual de cinzas no osso que, segundo Riet-Correa \& Timm (2007), deve ser igual ou superior a $60 \%$.

De acordo com Tokarnia et al. (2010) deve se suplementar $100 \mathrm{mg}$ de $\mathrm{Cu}$ por animal adulto/dia; desta forma, o consumo deste elemento no grupo que recebeu a MMC foi superior às necessidades diárias. No grupo suplementado com a MMS o consumo de $\mathrm{Cu}$ ficou abaixo do recomendado. Apesar destes valores se situarem acima e abaixo do recomendado não foram observados sinais clínicos de intoxicação ou de deficiência de $\mathrm{Cu}$, embora o período de avaliação tenha sido de apenas seis meses. Vale ressaltar que os animais que receberam somente $\mathrm{NaCl}$ também não manifestaram sinais de deficiência de $\mathrm{Cu}$, o que indica que a pastagem oferecida aos animais foi suficiente para suprir as necessidades de cu. Segundo Underwood (1977) valores de Cu em fígado bovino entre 0 e $50 \mathrm{mg} / \mathrm{kg}$ da matéria seca indicam deficiência, de 50 a $100 \mathrm{mg} / \mathrm{kg}$, sub-deficiência e níveis acima de $100 \mathrm{mg} / \mathrm{kg}$ são adequados. No referido estudo, as três formas de suplementação foram suficientes para atender as necessidades de $\mathrm{Cu}$ dos bovinos.

Nos grupos suplementados com a MMC e com a MMS as ingestões médias diárias de Co foram superiores às necessidades preconizadas por Tokarnia et al. (2010) que são de $5 \mathrm{mg} /$ dia. Porém, não foi observado efeito deletério do excesso deste elemento no grupo MMC, pois segundo os autores trata-se de um mineral de baixa toxicidade. Com relação ao grupo suplementado apenas com $\mathrm{NaCl}$, dois animais apresentaram sinais clínicos compatíveis com a deficiência de Co. Esse fato evidencia que o pasto dos capins Brachiaria (Urochloa) decumbens e Panicum maximum cv. Mombaça não continha Co suficiente para atender as necessidades dos bovinos. Talvez se o experimento durasse mais tempo, mais animais desenvolveriam sinais da deficiência de Co. De acordo com Malafaia et al. (2004), é comum pressupor-se, equivocadamente, que os problemas determinados por carência mineral aparecem tardiamente. Esta assertiva foi comprovada no referido trabalho com referência ao Co, onde dentro de poucos meses tornaram-se evidentes os sinais clínicos da deficiência de Co; esse deve ter sido o principal fator para o menor ganho de peso dos animais suplementados apenas com $\mathrm{NaCl}$ (Quadro 1). Segundo Underwood (1977) valores de Co no fígado de bovinos abaixo de $0,05 \mathrm{mg} / \mathrm{kg}$ indicam deficiência, de 0,05-0,12mg/kg sub-deficiência e acima de 
$0,10 \mathrm{mg} / \mathrm{kg}$ indicam índices adequados. Os altos valores nos animais suplementados com a MMS e MMC podem estar relacionados ao maior acúmulo deste elemento no fígado a partir da ingestão de quantidades superiores às exigidas pelos animais (Quadro2), que é de $5 \mathrm{mg}$ Co ani$\mathrm{mal} / \mathrm{dia}$.

Segundo Underwood (1977) valores de Zn no fígado de bovinos menores que $100 \mathrm{mg} / \mathrm{kg}$ indicam deficiência e valores acima de $100 \mathrm{mg} / \mathrm{kg}$ são considerados normais. Neste estudo todos os esquemas de suplementação foram suficientes para atender as exigências de $\mathrm{Zn}$ dos bovinos.

Valores hepáticos de até $0,10 \mathrm{mg} / \mathrm{kg}$ indicam deficiência de Se e valores acima são considerados normais em bovinos (Underwood, 1977). No referido estudo tanto as misturas minerais quanto a pastagem foram suficientes para atender as necessidades de Se para os bovinos. Moraes et al. (1999) determinaram as concentrações de Se no fígado de 107 bovinos que morreram de diversas enfermidades e encontraram 12 animais com valores de Se hepático abaixo do normal $(0,069 \mathrm{mg} / \mathrm{kg})$; nos demais animais os valores médios de Se foram de $0,62 \mathrm{mg} / \mathrm{kg}$ de MS.

Baseado na quantidade de elementos fornecidos e nos valores encontrados nos ossos e no fígado nos animais do Grupo 1 e Grupo 3, era de se esperar uma resposta similar com relação ao ganho de peso, já que os grupos foram mantidos nas mesmas condições de pastejo. Porém, o que se verificou foi que a média de ganho de peso do grupo de animais que receberam a MMS foi significativamente maior do que a média dos animais que receberam a MMC (Quadro 2). De acordo com Peixoto et al. (2003) e Tokarnia et al. (2010) essa diferença no desempenho entre os grupo de animais pode ser explicado pelo fato que, quando são adicionados vários minerais em uma mistura podem ocorrer prejuízos à saúde ou à produção dos animais, uma vez que elementos não deficientes na dieta e incluídos na mistura podem antagonizar outros elementos realmente necessários e, consequentemente, reduzir a absorção, o que pode diminuir a concentração sérica de um mineral realmente necessário, ocasionando em um aumento na ingestão para tentar suprir a demanda do organismo. Dessa forma, os elementos excedentes adicionados na MMC (Ca, S, Fe, Mn, Mg e I) podem ter contribuído para o menor ganho de peso dos animais que foram suplementados com essa mistura. Esses resultados confirmam a ideia proposta por Tokarnia et al. (2000), Peixoto et al. (2003) e Malafaia et al. (2004), de que não há relação entre o consumo de MMCs, muitas vezes ditas "completas", e o adequado desempenho ponderal dos animais.

\section{CONCLUSÃO}

Com base no prévio diagnóstico clínico-nutricional dos animais, o uso da mistura mineral seletiva demonstrou ser a melhor alternativa para a redução dos custos com a suplementação mineral em bovinos de corte criados em pastagens no Estado do Pará, sem comprometer o desempenho dos animais.

\section{REFERÊNCIAS}

AnualPec 2014. Anuário da Pecuária Brasileira. 21ạ ed. Informa Economics South America/FNP, São Paulo. 346p.

Bomjardim H.A., Oliveira C.M.C., Silveira J.A.S., Silva N.S., Duarte M.D., Faial K.C.F., Brito M.F. \& Barbosa J.D. 2015. Deficiências minerais em vacas em lactação da bacia leiteira do município de Rondon do Pará, estado do Pará. Pesq. Vet. Bras. 35(5):409-416.

Carvalho C.A.B., Peres A.A.C., Premazzi L.M., Malafaia P., Carvalho M.I.A.B., Paciullo D.S.C. \& Costa V.A.C. 2014. Performance of dairy heifers raised on Xaraéspalissadgrass (Brachiaria brizantha cv. Xaraés) pasture supplemented with two types of mineral mixture. Pesq. Vet. Bras. 34(1):46-50.

Fick K.R., McDowell L.R., Miles P.H., Wilkinson N.S., Funk J.D. \& Conrad J.H. 1979. Methods of Mineral Analysis for Plant and Animal Tissues. 3rd ed. Department of Animal Sciences, Univ. of Florida, Gainesville, FL.

Malafaia P., Costa R.M., Brito M.F., Peixoto P.V., Barbosa J.D. \& Tokarnia C.H. 2014. Equívocos arraigados no meio pecuário sobre deficiências e suplementação minerais em bovinos no Brasil. Pesq. Vet. Bras. 34(3):244-249.

Malafaia P., Peixoto P.V., Gonçalves J.C.S. \& Moreira A.L. 2004. Ganho de peso e custos em bovinos de corte submetidos a dois tipos de suplementos minerais. Pesq. Vet. Bras. 24(3):160-164.

McDowell L.R., Conrad J.H. \& Ellis G.L. 1984. Mineral deficiencies and imbalances and their diagnosis. Symposium on Herbivore Nutrition in Sub-Tropics and Tropics Problems and Prospects, FMC Gilchrist and RI Mackie, Pretoria, South Africa, p.67-88.

Moraes S.S., Tokarnia C.H. \& Döbereiner J. 1999. Deficiências e desequilíbrios de microelementos em bovinos e ovinos em algumas regiões do Brasil. Pesq. Vet. Bras. 19(1):19-33.

Nomura C.S., Silva C.S., Nogueira A.R.A. \& Oliveira P.V. 2005. Bovine liver sample preparation and micro-homogeneity study for $\mathrm{Cu}$ and $\mathrm{Zn}$ determination by solid sampling electrothermal atomic absorption spectrometry. Spectrochim. Acta B 60:673-680.

Peixoto P.V., Malafaia P., Miranda L.V., Canella C.C.F., Canella Filho C.C.F. \& Vilas Boas F.V. 2003. Eficiência reprodutiva de matrizes bovinas de corte submetidas a três diferentes tipos de suplementação mineral. Pesq. Vet. Bras. 23(3):125-130.

Radostits O.M., Gay C.C., Blood D.C. \& Hinchcliff K.W. 2007. Clínica Veterinária: um tratado de doenças dos bovinos, ovinos, suínos, caprinos e equinos. 9a ed. Guanabara Koogan, Rio de Janeiro. 1737p.

Riet-Correa F. \& Timm C.D. 2007. Deficiência de fósforo, p.248-257. In: Riet-Correa F., Schild A.L., Lemos R.A.A. \& Borges J.R.J. (Eds), Doenças de Ruminantes e Eqüídeos. $3^{\underline{a}}$ ed. Palloti, Santa Maria.

SAS 2010. Base SAS ${ }^{\circledR} 9.2$ Procedures Guide: statistical procedures. 3rd ed. SAS Institute, Cary, NC.

Tokarnia C.H. \& Döbereiner J. 1973. Diseases caused by mineral deficiencies in cattle raised under range conditions in Brazil, a review. Pesq. Agropec. Bras. 8(Supl.):1-6.

Tokarnia C.H., Döbereiner J. \& Peixoto P.V. 2000. Deficiências minerais em animais de fazenda, principalmente bovinos em regime de campo. Pesq. Vet. Bras. 20(3):127-138.

Tokarnia C.H., Döbereiner J., Moraes S.S. \& Peixoto P.V. 1999. Deficiências e desequilíbrios minerais em bovinos e ovinos: revisão de estudos realizados no Brasil de 1987 a 1998. Pesq. Vet. Bras. 19(2):47-62.

Tokarnia C.H., Peixoto P.V., Barbosa J.D., Brito M.F. \& Döbereiner J. 2010. Deficiências Minerais em Animais de Produção. Helianthus, Rio de Janeiro. 191p.

Underwood E.J. 1977. Trace elements in human and animals nutrition. 4th ed. AcademicPress, New York. 545p.

Valdes J.L., McDowell L.R. \& Koger M. 1988. Mineral status and supplementation of tropical condictions in Guatemala. I. Macroelements. J. Prod. Agric. 1(4):347-350.

Van Niekerk B.D.H. \& Jacobs G.A.1985. Protein, energy and phosphorus supplementation of cattle fed low-quality forage. S. Afr. J. Anim. Sci. 15(4):133-136. 